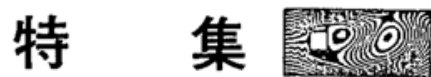

\section{構造基本断面の空力特性（その 3) \\ Aerodynamic characteristics of fundamental structures \\ (Part 3)}

\section{6. 気流の乱れの効果}

武田 勝昭*

Katsuaki TAKEDA

以下の成果はNKK応用技術研究所において得られたものである。

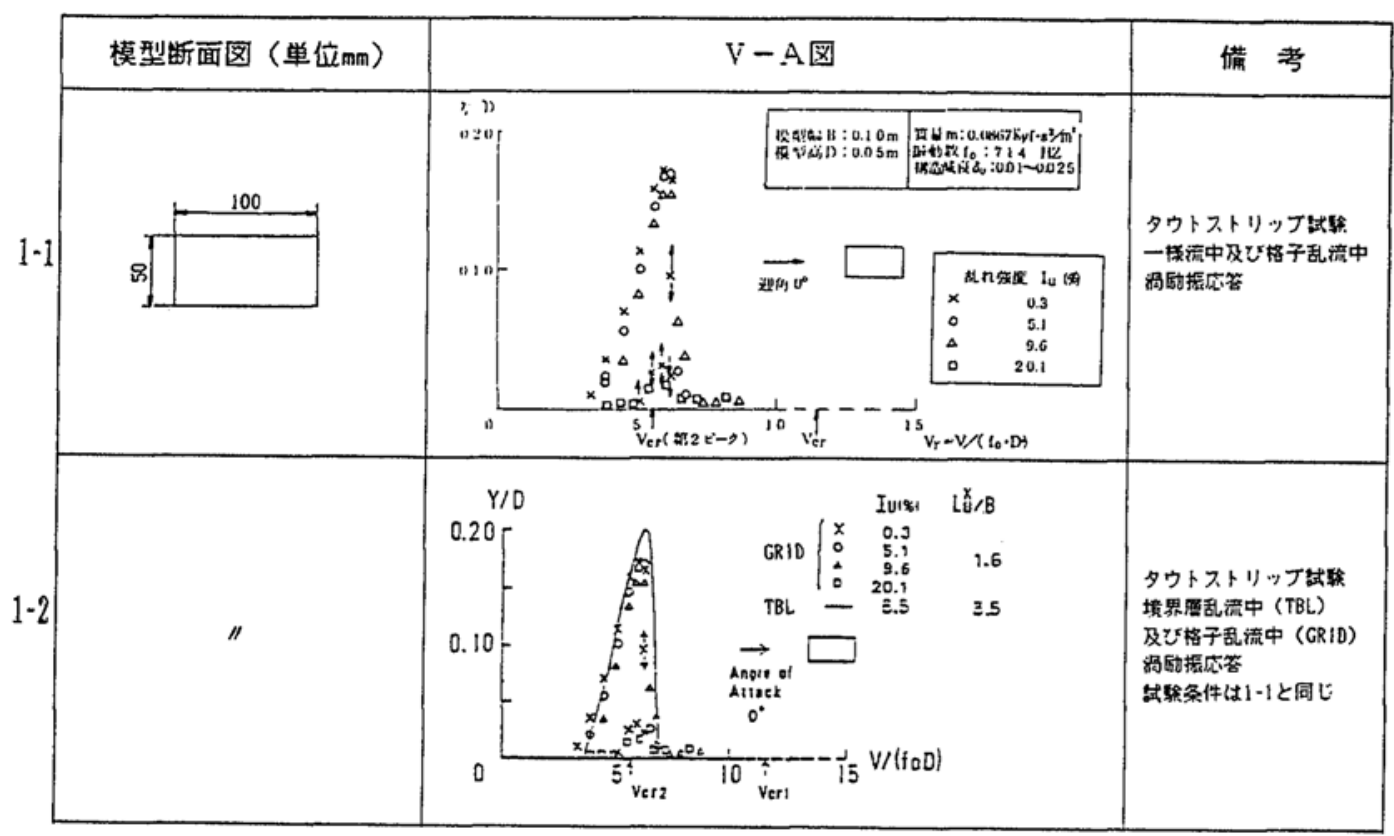

$* \mathrm{~N} \mathrm{~K} \mathrm{~K}$ 応用技術研究所, 課長

Engineering Research Center, NKK 


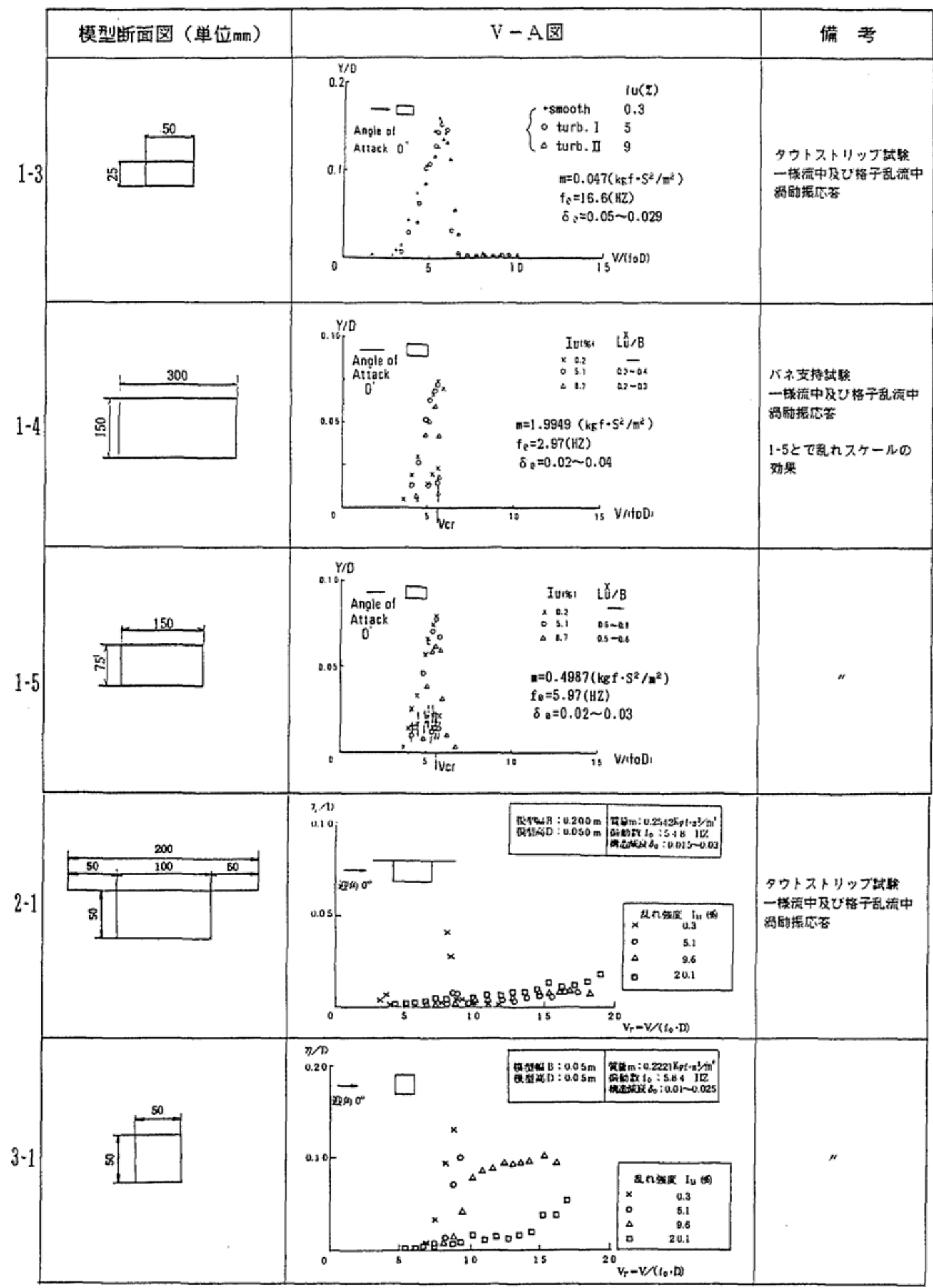




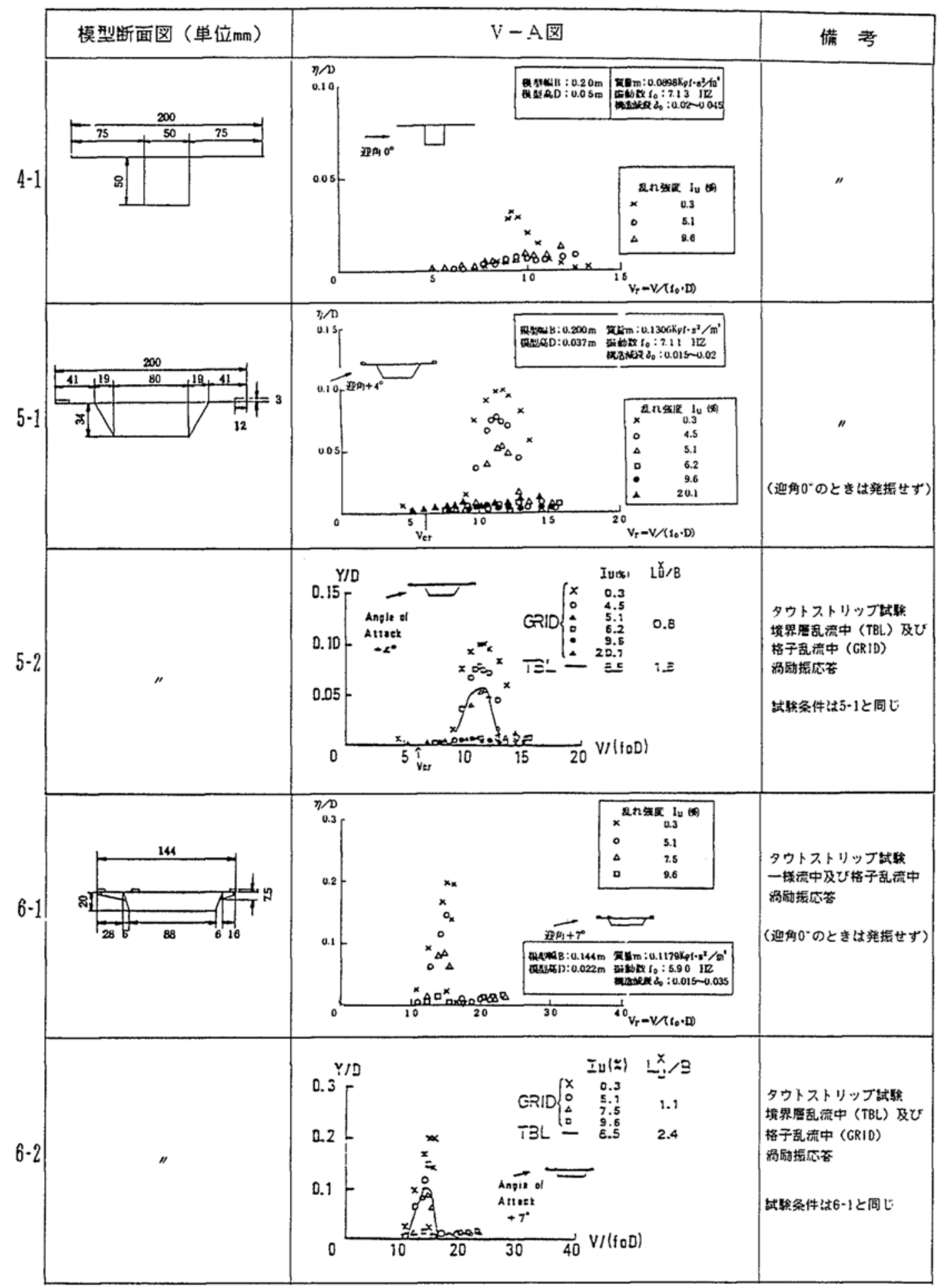




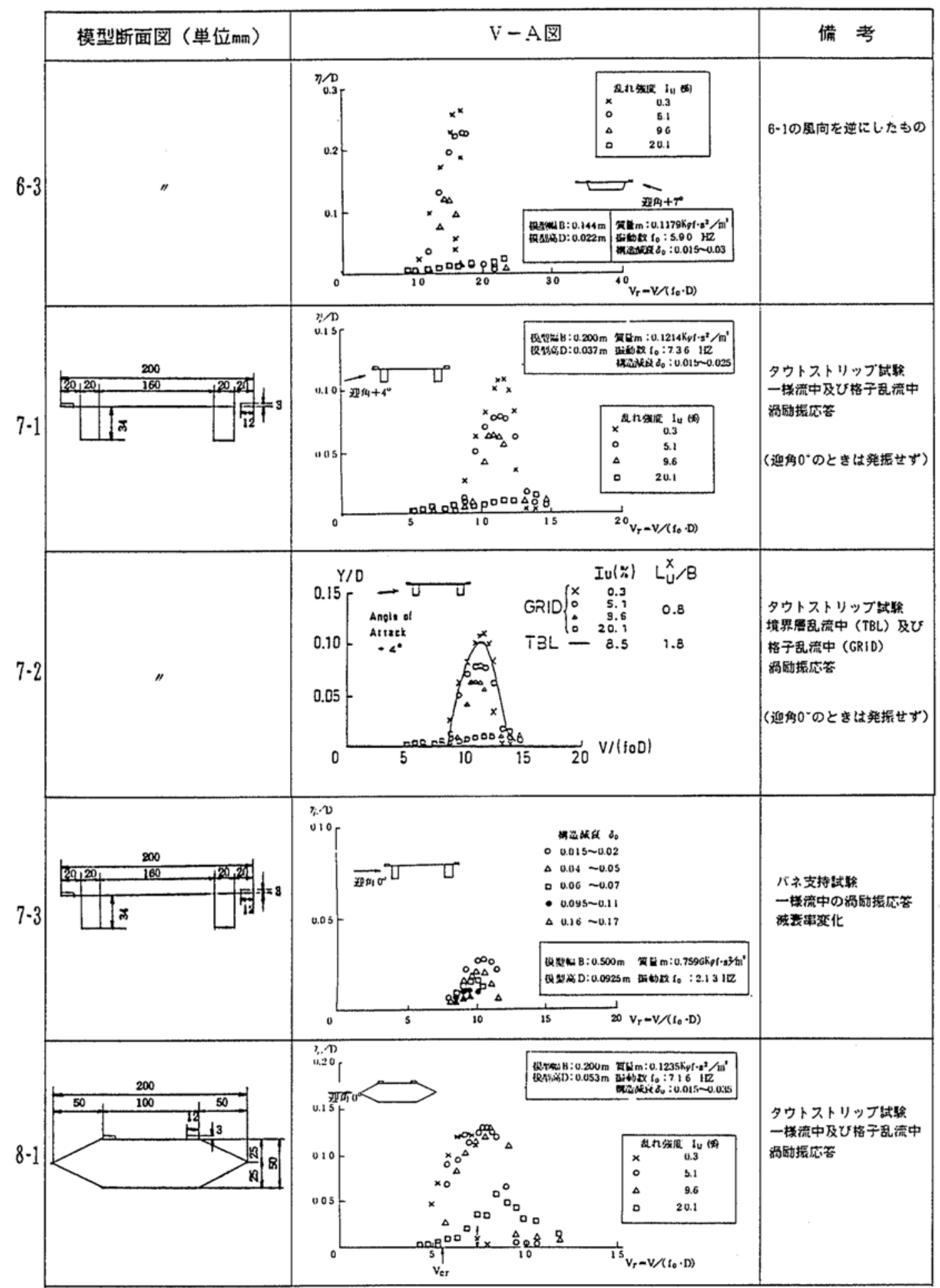




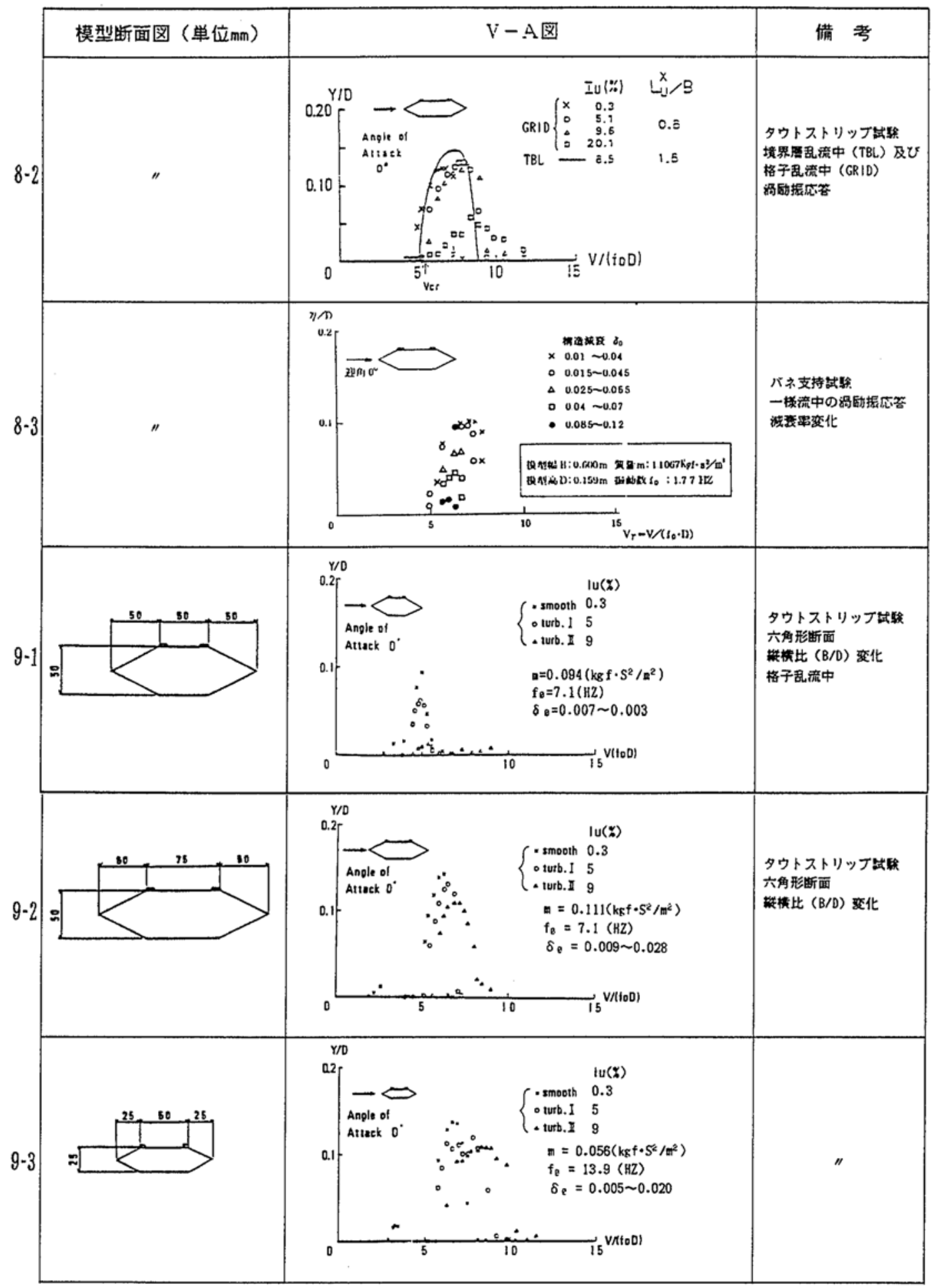




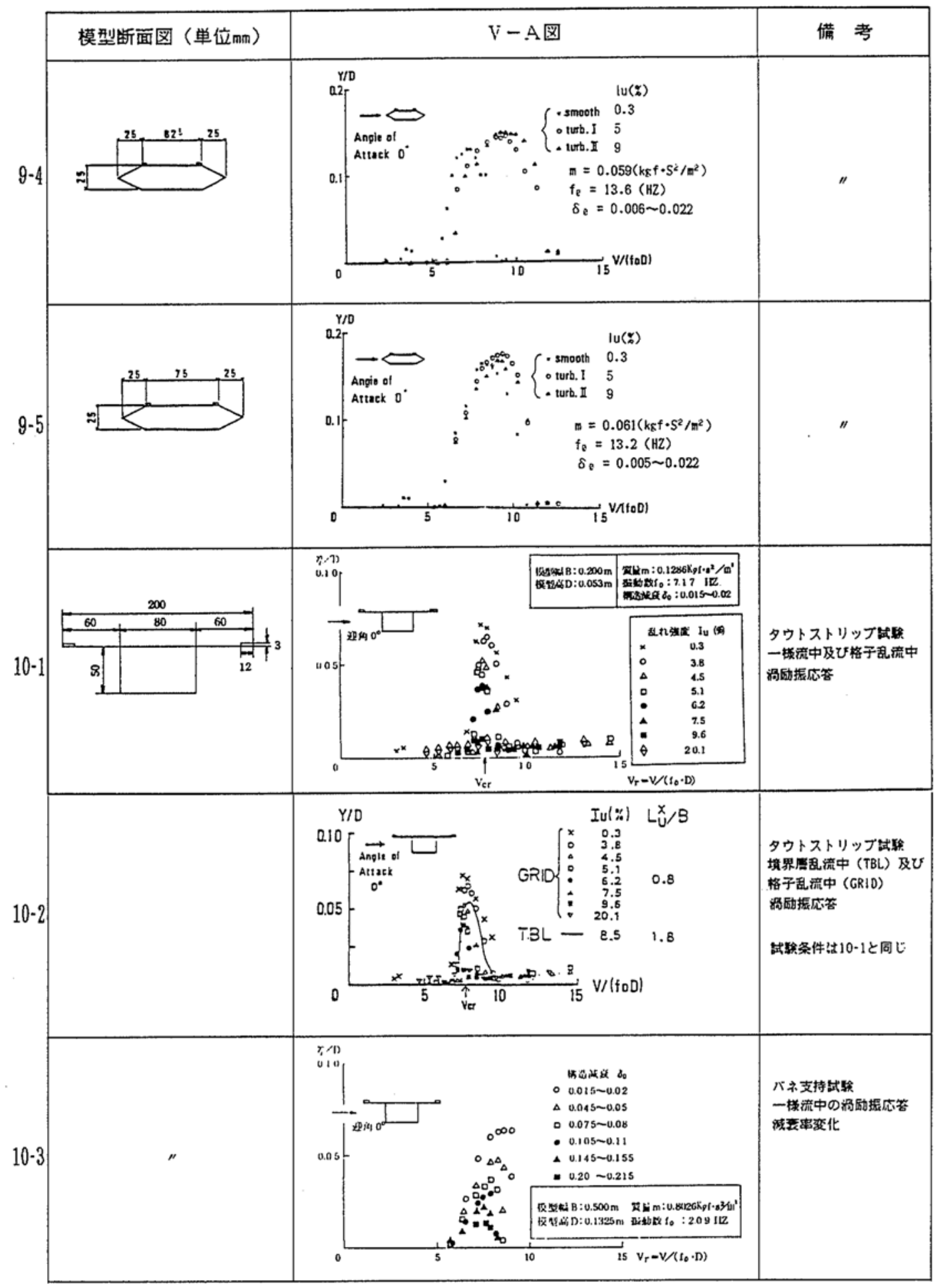




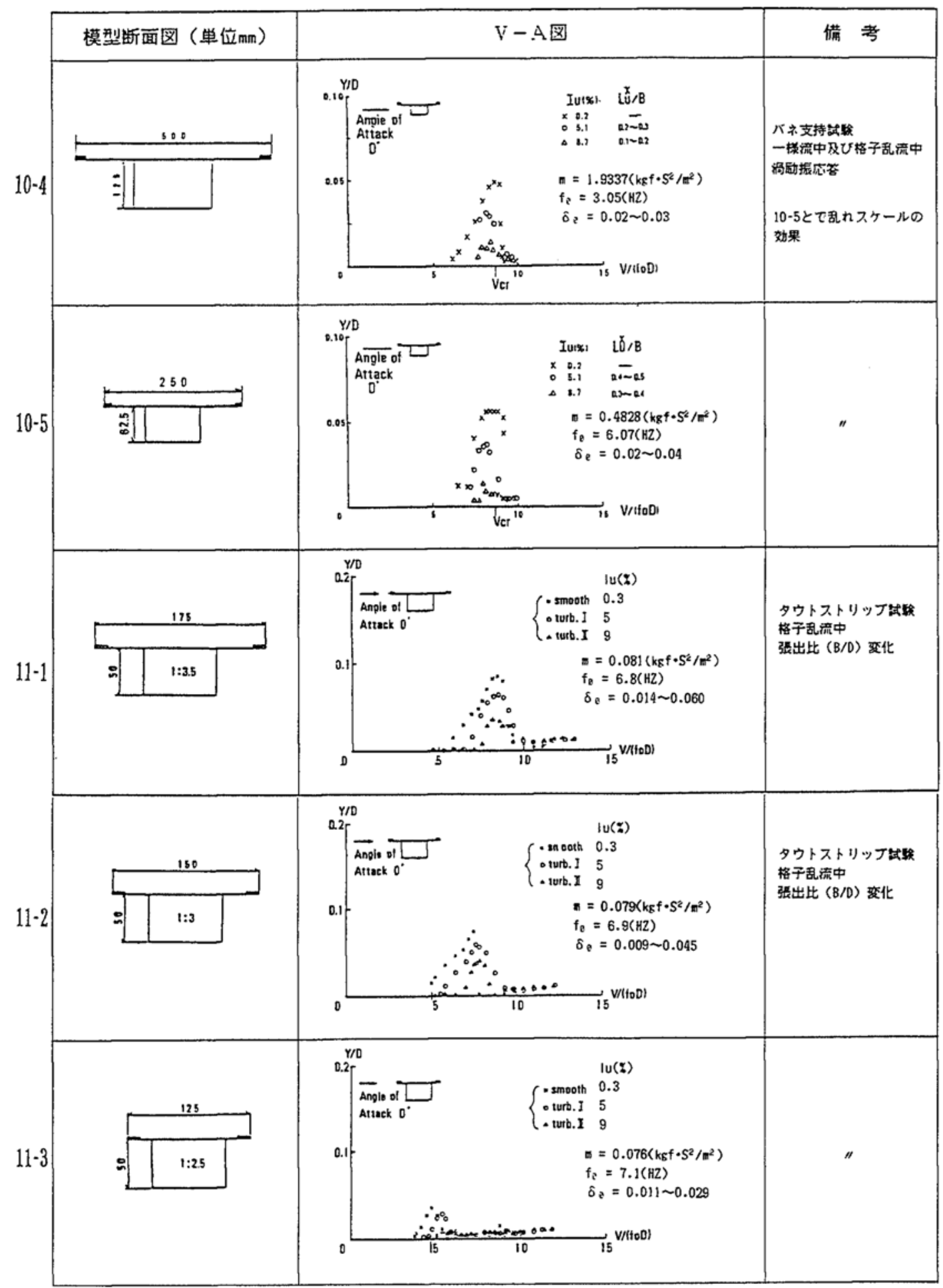




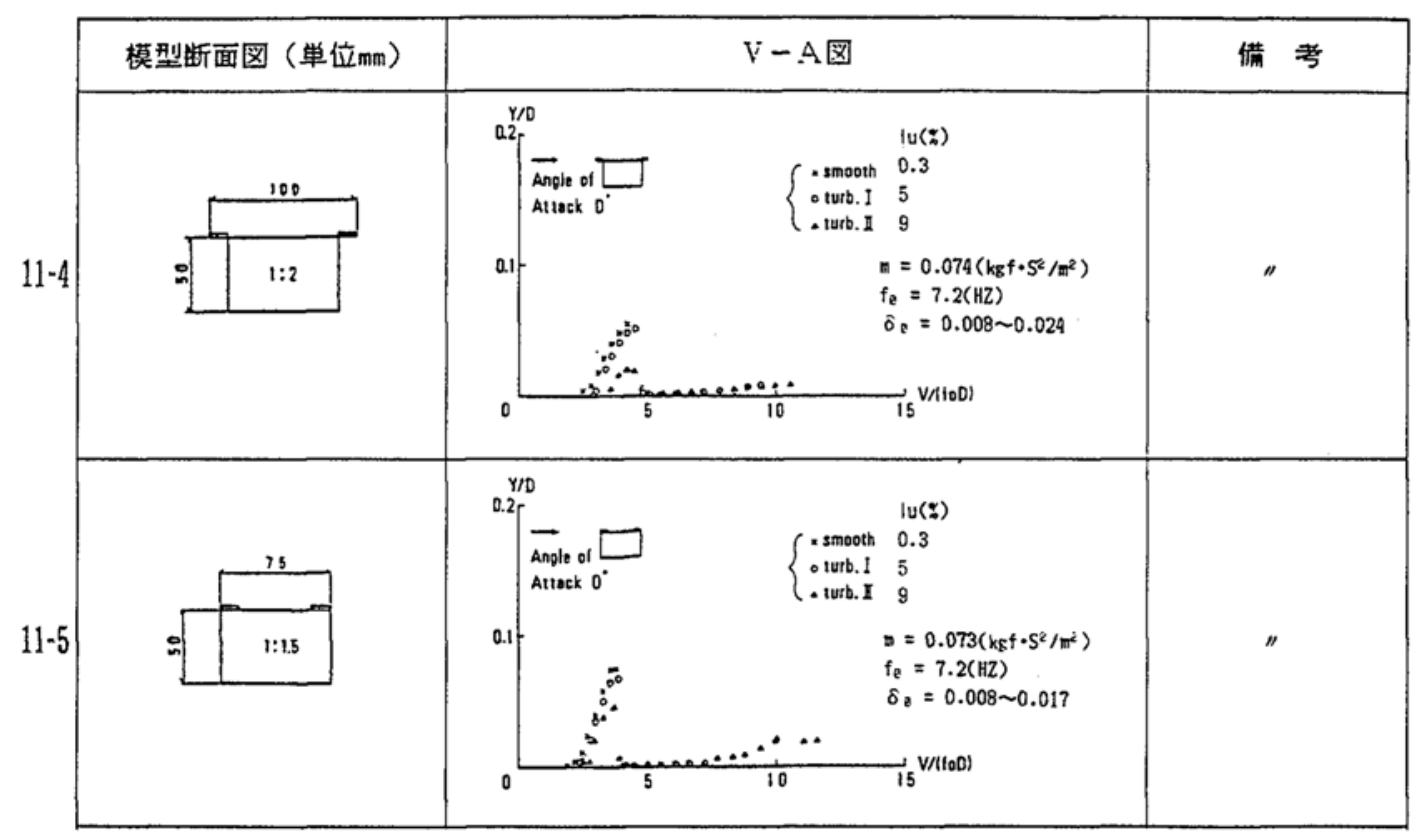

